\title{
WACANA MARTABAT TUJUH DI JAMBI
}

\author{
Oleh: \\ Ali Muzakir \\ Dosen Universitas Islam Negeri STS Jambi \\ Email: muzakir_adab@uinjambi.ac.id
}

\begin{abstract}
Memasuki abad ke-17 merupakan periode yang normatif bagi pembentukan pikiran dan praktik tasawuf dan tarekat. Guruguru sufi terlibat aktif tidak hanya dalam mengintelektualisasi berbagai disiplin ilmu-ilmu keislaman tetapi juga gerakan reformasi praktik-praktik tasawuf yang harmonis dengan akidah dan syari'ah. Tulisan ini menganalisis karya-karya ulama Jambi yang turut merespon doktrin-doktrin tasawuf yang dipandang rumit tersebut. Pendekatan kajian ini adalah bersifat kronologi pemikiran tentang doktrin martabat tujuh dari sejak awal diperkenalkan hingga penyebarannya. Dalam konteks pemikiran Islam di Indonesia, kajian tentang ulama-ulama Jambi masih sangat jarang. Untuk itu, tulisan ini akan mengungkap beberapa karya ulama Jambi baik yang masih dalam bentuk manuskrip maupun cetak yang belum banyak dikenal. Tujuannya adalah sebagai teropong untuk melihat seberapa besar pengaruh pemikiran Islam dari pusat-pusat wacana Islam (the center of Islamic discourse), seperti Aceh, Palembang, dan Minangkabau, terhadap wilayah-wilayah lainnya di Indonesia.
\end{abstract}

Keywords: Tasawuf, Tarekat, Martabat Tujuh, Zayn al-Jambi

\section{A. Pendahuluan}

Guru-guru sufi dan tarekat sangat berperan dalam menegosiasikan perkembangan Islam di kawasan Melayu-Indonesia. Karena peran mereka yang sangat menonjol, Johns menjadikan tasawuf dan tarekat menjadi kategori dan sumber yang sangat penting untuk mengungkap pemikiran dan dinamika umat Islam di Nusantara. ${ }^{1}$ Memasuki abad ke-17

1 Martin van Bruinessen, Tarekat Naqsyabandiyah di Indonesia: Survei Historis, merupakan periode yang normatif bagi pembentukan pikiran dan praktik tasawuf dan tarekat. Guru-guru sufi terlibat aktif tidak hanya dalam mengintelektualisasi berbagai disiplin ilmu-ilmu keislaman tetapi juga gerakan reformasi praktik-praktik tasawuf yang harmonis dengan akidah

Geografis, dan Sosiologis. Bandung: Mizan, 1994); A. H Johns, "Sufism as Category in Indonesian Literature and History," JSEAH, vol. II, no. 2, (1961): 14-15; Hawash Abdullah, Perkembangan Ilmu Tasawuf dan Tokohtokohnya di Nusantara (Surabaya: Al-Ikhlas, t. th.) 
dan syari'ah. ${ }^{2}$ Karena itu tidak berlebihan bila Bakar menyebut bahwa tasawuf memang telah mengkristal dalam sejarah dan peradaban Islam di kawasan Melayu-Indonesia. ${ }^{3}$

Pengajaran tasawuf yang menggali inti dari pengalaman spiritual beragama menjadi daya tarik tersendiri bagi Muslim-Melayu. ${ }^{4}$ Karena sifatnya tersebut, tasawuf dipandang sebagai ilmu yang lebih khusus (khash) dan hanya akan diajarkan kepada orangorang yang dipandang telah siap untuk menerimanya, agar tidak menimbulkan kesalahpahaman dan kontroversial. Dipandang kontroversial karena pada level yang tinggi, tasawuf mengajarkan hubungan yang rumit tentang asal-usul makhluk/alam dan hubungannya dengan Tuhan, misalnya konsep hulul, ittihad, tajallî, wahdat al-wujud, dan martabat tujuh. Konsep tersebut dipandang sebagai bagian dari proses perjalanan manusia untuk mencapai pengalaman spiritual tertinggi dan insan kamil (manusia sempurna). Doktrin-doktrin yang kontroversial tersebut sering memicu polemik dan pengkafiran, terutama, jika diajarkan secara longgar kepada orang-orang kebanyakan ('awam). Karena itu,

2 Azyumardi Azra, The Origins of Islamic Reformism in Southeast Asia: Networks of Malay and Middle Eastern 'Ulama' in the Seventeenth and Eighteenth Centuries (Honolulu: Allen \& Unwin, 2004), 52.

${ }^{3}$ Osman Bakar, "Sufism in the MalayIndonesian World," in S. H. Nasr (ed.), Islamic Spirituality II: Manifestations, (London: SCM, 1991), 259.

4 A. H. Johns, "Sufism in Southeast Asia: Reflections and Reconsiderations," JSEAS, Vol. 26, No. 1, (1995): 176-183).

5 A. H Johns, "Reflection on Mysticism of Shams al-Din al-Samatra'I (1550?-1630)," Studia Islamika, vol. 18, no. 2, (2011): 231-232; S. M. N al-Attas, "Raniri and the Wujudiyyah of the $17^{\text {th }}$ Century Acheh," guru-guru sufi mensyaratkan secara ketat, misalnya kepatuhan pada syari'ah, sebelum masuk dunia tasawuf. Dengan demikian, pada dasarnya polemik-polemik yang melibatkan guru-guru sufi mengambil bentuk reformasi pemahaman keagamaan, yang bertujuan untuk menemukan harmonisasi antara tasawuf dan syari'ah, sehingga menepis kecurigaan bahwa doktrin-doktrin tasawuf-filosofis akan membawa kepada kesesatan teologis. ${ }^{6}$

Tulisan ini menganalisis karyakarya ulama Jambi yang turut merespon doktrin-doktrin tasawuf yang dipandang rumit tersebut. Pendekatan kajian ini adalah bersifat kronologi pemikiran tentang doktrin martabat tujuh dari sejak awal diperkenalkan hingga penyebarannya. Dalam konteks pemikiran Islam di Indonesia, kajian tentang ulama-ulama Jambi masih sangat jarang. Untuk itu, tulisan ini akan mengungkap beberapa karya ulama Jambi baik yang masih dalam bentuk manuskrip maupun cetak yang belum banyak dikenal. Tujuannya adalah sebagai teropong untuk melihat seberapa besar pengaruh pemikiran Islam dari pusat-pusat wacana Islam (the center of Islamic discourse), seperti Aceh, Palembang, dan Minangkabau, terhadap wilayahwilayah lainnya di Indonesia. ${ }^{7}$ Karya-

Monograph of MMBRAS, no. 3, Singapore, (1966): 43-79.

6 Oman Fathurahman, Tanbih alMasyi: Menyoal Wahdatul Wujud, Kasus Abdurrauf Singkel di Aceh Abad 17. Bandung: Mizan, 1999; Ito, Takeshi. "Why did Nuruddin ar-Raniri leave Aceh in 1054 A.H.?" in Bijdragen tot de Taal-, Land-en Volkenkunde, 134, 4 (1978): 489-491.

7 Jane Drakard, Sejarah Raja-raja Barus: Dua Naskah dari Barus (Jakarta: EFEO, 1988), 14. 
karya ulama adalah sumber yang sangat otentik untuk merekonstruksi dinamika intelektual dan wacana Islam di Nusantara. ${ }^{8}$ Sahlins mengingatkan bahwa peristiwa-peristiwa pinggiran dan kecil bisa saja meningkatkan pemahaman tentang berbagai proses historis yang lebih besar. ${ }^{9}$

\section{B. Post-human Polemics}

Hamzah Fansuri ${ }^{10}$ adalah sufi pertama di Nusantara yang berhasil mengutarakan doktrin-doktrin tasawuf yang rumit. Karya-karyanya bergaya puitis dan penuh alegoris ${ }^{11}$ dan secara

8 Ayumardi Azra, "Naskah dan Rekonstruksi Sejarah Sosial-Intelektual Nusantara," dikutip dalam Uka Tjandrasasmita, Kajian Naskah-naskah Klasik dan Penerapannya bagi Kajian Sejarah Islam di Indonesia (Jakarta: Puslitbang Lektur Keagamaan, Kemenag RI, 2006), 9. Oman Fathurahman, "Naskah dan Rekonstruksi Islam Lokal: Telaah Awal atas Kitab Ithaf al-Zaki karya Ibrahim al-Kurani," Makalah Simposium MANASSA, Universitas Andalas, Padang, 31 Juli 2001.

9 Marshall Sahlins, Islands History (Chicago: University of Chicago Press, 1985), 2.

10 Beberapa sarjana berbeda dalam menentukan tahun wafatnya. Guillot Guillot dan Ludvik Kalus menyebut Hamzah Fansuri wafat pada tahun 1527, lihat, Inskripsi Islam Tertua di Indonesia, penerj. Laddy Lesmana, dkk. (Jakarta: KPG, 2008), 20-21. Peneliti lain menyebutkan antara 1590 sampai 1610. Azyumardi Azra, The Origins of Islamic Reformism in Southeast Asia: Networks of Malay and Middle Eastern 'Ulama' in the Seventeenth and Eighteenth Centuries (Honolulu: Allen \& Unwin, 2004), 62; V.I. Braginsky, "Towards the Biography of Hamzah Fansuri. When Did Hamzah Live? Data from His Poems and Early European Accounts," Archipel, Vol. 57, (1999): 135-175.

11 S. M. N al-Attas, The Mystic of Hamzah Fansuri (Kuala Lumpur: University of Malaya Press, 1970); Abdul Hadi W.M., Tasawuf yang Tertindas: Kajian Hermeneutik sengaja ditulis dalam Bahasa Melayu agar mudah dipahami oleh Muslim di Nusantara. ${ }^{12}$ Setelah Hamzah Fansuri muncul Syams al-Din al-Sumatrani (w. 1040/1630). Syams al-Din lebih leluasa mengembangkan ajaran-ajaran tasawufnya karena ia ditunjuk selama ulama di Kesultanan Aceh. ${ }^{13}$ Hamzah Fansuri berafiliasi ke dalam Tarekat Qadiriyah, ${ }^{14}$ sedangkan Syams al-Din mengikut Naqsyabandiyah. Syams alDin dilaporkan sempat menginisiasi sultan Iskandar Muda (berkuasa 16071636) ke dalam tarekatnya. ${ }^{15}$

Hamzah Fansuri dan Syams alDin sama-sama berada pada alur mazhab tasawuf-filosofis. ${ }^{16}$ Hamzah Fansuri banyak menjelaskan konsep wahdat al-wujud dari Ibn 'Arabi (w. 638/1240), sedangkan Syam al-Din lebih tertarik menjelaskan konsep martabat tujuh. Martabat tujuh merupakan perumusan lebih detail mengenai asal-susul alam dan hubungannya dengan Tuhan, yang dirumuskan oleh Muhammad Fadhl

terhadap Karya-karya Hamzah Fansuri (Jakarta: Paramadina, 2001).

${ }^{12}$ S. M. N al-Attas, The Misticism of Hamzah Fansuri, 298.

${ }^{13}$ C. A. O Nieuwenhuijze, Samsu'l Din van Pasai, Bijdrage tot de Kennis der Sumatransche Mystiek (Leiden: E. J. Brill, 1945), 234.

14 Azyumardi Azra, The Origins of Islamic Reformism, 62. Abdul Hadi WM dan L.K Ara (penyt.), Hamzah Fansuri: Penyair Sufi Aceh (t. tmp. Lotkala), 6.

15 Peter. G. Riddell, Islam and the Malay-Indonesian World: Transmission and Responses (Honolulu: University of Hawaii Press, 2001), 111.

16 A. H Johns, "Malay Sufism as Illustrated in an Anonymous Collection of $17^{\text {th }}$ Century Tract," JMBRAS, vol. XXX, part 2, (1957): 9-10; S. M. N al-Attas, Raniri and the Wujudiyyah of the $17^{\text {th }}$ Century Acheh, Monograph of MMBRAS, no. 3, Singapore, 1966, 43-79. 
Allah al-Burhanpuri (w. 1028/1619). Syams al-Din menjadikan karya sufi asal India tersebut, yang berjudul Tuhfah al-Mursalah ila Ruh al-Nabi, sebagai rujukan penting dalam memahami konsep wahdat al-wujud. ${ }^{17}$ Ajaran atau salinan naskah Tuhfah alMursalah kemungkinan masuk ke Aceh sebelum tahun 1030/1619. ${ }^{18}$ Baik wahdat al-wujud maupun martabat tujuh segera menjadi wacana tasawuf yang banyak menarik perhatian sufisufi Nusantara, dengan berbagai komentarnya masing-masing. Al-Attas menyebut Hamzah Fansuri dan alSumatrani adalah sufi Nusantara yang paling bertanggung jawab dalam memperkenalkan doktrin wahdat alwujud dan martabat tujuh di Aceh. ${ }^{19}$ Martabat tujuh menjelaskan tentang satu wujud dengan tujuh martabatnya. Tujuh martabat tersebut ialah ahadiyyah, wahdah, wâhidiyyah, alam arwâh, alam mitsâl, alam ajsâm, dan alam insân. Dahlan yang mengutip salah satu karya Syams al-Din menguraikannya sebagai berikut:

I'lam, ketahui olehmu bahwa [se]sungguhnya martabat wujud Allah itu tujuh martabat, pertama martabat ahadiyah, kedua martabat wahdah, ketiga

17 C. A. O. Nieuwenhuijze, Samsu'l Din van Pasai; Abdul Aziz Dahlan, Penilaian Teologis atas Paham Wahdat al-Wujud (Kesatuan Wujud): Tuhan-Alam-Manusia dalam Tasawuf Syamsuddin Sumatrani (Padang: IAIN IB Press, 1999), 51-102.

18 A. H. Johns, "Malay Sufism as Illustrated in an Anonymous Collection of $17^{\text {th }}$ Century Tracts," JMBRAS, Singapore, 178, vol. XXX, part II, (1957): 31-33.

S.M.N al-Attas, Raniri and (Singapore: JMBRAS, 1966); Mysticism of Hamzah Fansuri (Kuala Lumpur: University of Malaya Press, 1970); A Commentary on the H\{ujjat al-Shiddiq of Nur al-Din al-Raniri (Kuala Lumpur: Ministry of Culture, 1986). martabat wahidiyyah, dan keempat martabat alam arwâh, dan kelima martabat alam mitsâl, dan keenam martabat alam ajsâm, dan ketujuh martabat alam insan. Maka ahadiyyah bernama hakikat Allah Ta'ala, martabat dzat Allah Ta'ala dan wahdah itu bernama hakikat Muhammad, ia itu bernama sifat Allah dan wahidiyyah itu bernama <hakikat> insan dan Adam 'alayh al-salam dan kita sekalian, ia itu bernama asma` Allah Ta'ala. Maka 'ala arwah martabat <hakikat> segala nyawa, maka 'alam mitsal itu martabat <hakikat> segala rupa, maka 'alam ajsam itu martabat <hakikat> segala tubuh, maka alam insan itu martabat <hakikat> segala manusia. Adapun martabat ahadiyyah itu martabat azal al-azal dan wahdah itu martabat azal Allah dan wâhidiyyah itu martabat ahad Allah. Maka 'alam arwâh $<$ dan> 'alam mitsâl martabat ahad, maka 'alam ajsam dan 'alam insan martabat abad alabad. Adapun martabat ahadiyyah <dan> wahdah dan wahidiyyah itu anniyat Allah Ta'ala maka 'alam arwah dan 'âlam mitsâl dan 'âlam ajsâm dan 'alam insân itu martabat anniyat al-makhluq. ${ }^{20}$

Kutipan tersebut diuraikan sebagai berikut: martabat pertama adalah martabat ahadiyyah (keesaan)

\footnotetext{
20 Abdul Aziz Dahlan, Penilaian Teologis atas Paham Wahdat al-Wujud (Kesatuan Wujud) Tuhan, Alam, Manusia dalam Tasawuf Syamsuddin Sumatrani (Padang: IAIN-IB Press, 1999), h. 50.
} 
yaitu wujud objektif Tuhan; bukan sesuatu yang diidekan atau dikonsepkan oleh manusia tentang Tuhan. Wujud objektif Tuhan adalah dzat-Nya sendiri, yang menjadi dasar bagi munculnya segala macam manifestasi (tajalli). ${ }^{21}$ Martabat kedua adalah martabat wahdah, merupakan tajalli diri Tuhan. Martabat ini adalah penampakan diri di dalam diri atau dzat-Nya, yang bersifat global. Guruguru sufi mengibaratkannya seperti huruf-huruf yang banyak tetapi masih bersatu dalam tinta yang terdapat di mata pena. Martabat ketiga adalah wâhidiyyah, yaitu munculnya pengetahuan yang terperinci dalam diri Tuhan tentang sifa-sifat dan namanama-Nya. Martabat ini menghasilkan pengetahun yang terperinci tentang hakikat-hakikat alam (a'yân tsâbitah). Akan tetapi a'yân tsâbitah tidak memiliki wujud aktual; bahkan belum mencium aroma wujud. ${ }^{22}$ A'yân tsâbitah dapat pula dipahami sebagai rancangan tetap dan lengkap tentang alam; dan alam tersebut akan diwujudkan oleh Tuhan secara aktual. ${ }^{23}$ Ketiga martabat tersebut bersifat qadim (dahulu tanpa permulaan atau tanpa didahului oleh tiada). Masing-masing martabat tidak saling mendahului. Sebutan pertama, kedua, dan ketiga tidaklah mengacu pada urutan waktu (zaman), tetapi muncul berdasarkan urutan akal dan spiritual manusia tentang aspek mana yang menjadi dasar bagi aspek yang lain.

Pada tahap berikut adalah proses terciptanya alam. Karena itu,

\footnotetext{
Teologis, h. 54 .

22 Abdul Aziz Dahlan, Penilaian

Teologis, h. 55.

23 Abdul Aziz Dahlan, Penilaian

Teologis, h. 56.
}

21 Abdul Aziz Dahlan, Penilaian jika pada tiga martabat sebelumnya tidak diistilah dengan alam, tetapi memasuki martabat keempat digunakan istilah alam dengan nama 'alam arwah. Makhluk pertama yang muncul adalah berupa nur (cahaya), yang disebut dengan beberapa nama yaitu Ruh Muhammad, Nur Muhammad, dan alQalam al-A'la (Pena Tertinggi). Nur Muhammad yang tercipta bersamaan dengan segala arwah. Alam arwah meliputi pula para malaikat, jin, setan, ruh manusia, ruh binatang, dan ruh tumbuh-tumbuhan. Di antara ciptaan segala arwah tersebut, martabat tertinggi adalah kalangan arwah manusia, kemudian para malaikat, jin, dan terakhir setan. ${ }^{24}$

'Alam mitsâl merupakan alam segala rupa, alam segala contoh, atau alam segala bentuk. 'Alam mitsâl digambarkan sebagai sesuatu yang murakkab (tersusun), lathîf (halus), ghayr mutajazzi (tidak mengandung bagian-bagian), lâ muba' adh (tidak dapat dibagi), lâ mukhraq (tidak bisa dipisah-pisah), lâ muta'im (tidak bias bersatu dengan yang lain), dan masih termasuk alam ghaib. Dengan demikian dapat dipahami, bahwa alam mitsâl tidak bisa disentuh dan ditangkap oleh panca indera lahir. ${ }^{25}$ Sesuatu yang dapat ditangkap oleh panca indera adalah 'alam ajsam (tubuh-tubuh materi). Nama lain yang digunakan ialah âlam al-syahâdah (yang disaksikan) atau alam empiris, yang berarti telah bersifat materi. Alam empiris meliputi juga 'arasy, tujuh lapis langit dan bumi.

Martabat yang terakhir adalah 'âlam al-insân. Semua penjelasan

24 Abdul Aziz Dahlan, Penilaian Teologis, h. 91-92.

${ }_{25}$ Abdul Aziz Dahlan, Penilaian

Teologis, h. 93. 
rumit tentang martabat tujuh pada intinya bermuara pada pembicaraan tentang posisi penting manusia di alam semesta. Makrifat Allah melalui batin, sebagai tujuan tertinggi dalam tasawuf, tidak mungkin diperoleh tanpa mengenal diri sendiri, dengan terkenal من عرف نفسه فقد عرف " dengan ungkapan "ربه (siapa yang mengenal dirinya, pastilah ia mengenal Tuhannya). Pengenalan diri sendiri itu maksudnya mengenal aspek ruh/batin/jiwa-nya. Penciptaan manusia merupakan realisasi dari kehendak Tuhan untuk ber-tajallî pada bukan diri-Nya dengan tajallî yang paling jelas. Karena itu ada ungkapan hadits qudsi: ما ظهرت في شئ

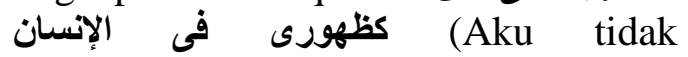
menampakkan diri pada sesuatu seperti penampakan-Ku melalui manusia). ${ }^{26}$ Dengan kata lain dapat dipahami, meskipun manusia sebagai martabat ketujuh tajallî wujud Tuhan tapi ia merupakan "karya" tertinggi. TajallîNya melalui manusia lebih tampak dari pada alam yang lain. Setiap manusia memiliki potensi mendekatkan diri sedekat-dekatnya, bahkan menyatu dengan Tuhan. Hanya manusia pula yang dapat meniru dan menampilkan "nama-nama" dan "sifat-sifat" Tuhan. 'Alam al-insân disebut juga syay' jâmi', yakni sesuatu yang menghimpun semua martabat tajallî: wahdah, wâhidiyah, ruh nurani, dan tubuh yang gelap. Nama Tuhan yang ber-tajallî melalui 'âlam al-insân adalah nama alJâmi' (Yang Maha Menghimpun). ${ }^{27}$ Tentunya manusia yang bisa menampakkan tajallî-Nya berbedabeda. Manusia yang mengenal diri sendiri dan menyucikan dirinya akan semakin jelas meniru dan menampilkan

\section{Teologis, h. 93.}

26 Abdul Aziz Dahlan, Penilaian

${ }^{27}$ Ibid., h. 103 sifat-sifat dan nama-nama Tuhan dalam segala perbutannya. Peniruan sifat dan nama Tuhan akan melahirkan manusia yang sempurna (insân al-kamîl). ${ }^{28}$ Uraian Syams al-Din tentang martabat tujuh disebut lebih rinci daripada alBurhanpuri. Secara objektif Johns mengatakan: "It is interesting to note that Shamsu'l Din's work far more developed better constructed than that Ibn Fadli'llah."29

Pengajaran paham wahdat alwujud maupun martabat tujuh mendapatkan kecaman yang sangat keras dari Nur al-Din al-Raniri (w. 1068/1658). Dilihat dari latar belakang pemikirannya, sebenarnya, al-Raniri adalah juga seorang sufi dan pengikut Tarekat Rifa'iyah, tetapi dalam gerak pemikirannya ia lebih menekankan pada prinsip-prinsip ortodoksi Islam. Karena itu al-Raniri mempersyaratkan secara mutlak prinsip-prinsip tawhid dan praktik syari'ah terlebih dahulu, apa pun orientasi paham keagamaan seseorang. ${ }^{30}$ Al-Raniri menilai karyakarya Hamzah Fansuri dan alSumatrani, telah mengaburkan prinsipprinsip imanensi (tasybîh) dan transendensi (tanzîh) Tuhan dengan alam. ${ }^{31}$ Para pengikut Hamzah Fansuri

${ }^{28}$ Yunasril Ali, Manusia Citra Ilahi: Pengembangan Konsep Insan Kamil Ibn 'Arabi oleh al-Jili (Jakarta: Paramadina, 1997), h. 49.

29 A.H Johns, The Gift Adressed to the Spirit of the Prophet (Canberra: The Australian National University, 1965), 9; uraian yang rinci dari al-Sumatrani dapat dilihat dalam Abdul Aziz Dahlan, Penilaian Teologis, 50-58 dan 85-97.

30 Azyumardi Azra, The Origins of Islamic Reformism, 67.

31 S.M.N. Al-Attas, Raniri and Wujudiyyah of $17^{\text {th }}$ Century Acheh, Singapore, JMBRAS, (1966): 15-42. Lebih jauh tentang konsep-konsep tasawuf Nur al-Din al-Raniri lihat Ahmad Daudy, Allah dan Manusia dalam 
dan al-Sumatrani banyak yang diancam bunuh dan karya-karya mereka dibakar di halaman masjid Baiturrahim. ${ }^{32}$

Post-human polemics yang melibatkan Hamzah Fansuri dan Syams al-Din, dan al-Raniri di Aceh pada abad ke-17 menunjukkan bahwa dari sejak awal penulisan karya-karya tasawuf di Nusantara telah membahas topik-topik yang rumit dan berat, yaitu pengajaran tentang hakikat alam (manusia) dan hubungan ontologis antara Tuhan dengan alam dan manusia. Persoalan-persoalan mendapatkan daya tariknya di dalam pengajaran wahdat al-wujud dan martabat tujuh. Sebenarnya, doktrin wahdat al-wujud dan martabat tujuh adalah dua tema yang juga didiskusikan secara luas di dunia Islam, akan tetapi di Aceh telah menjadi pembicaraan yang rumit dan kontroversial di kalangan masyarakat. ${ }^{33}$

Tasawuf filosofis yang diajarkan oleh Hamzah Fansuri dan alSumatrani memang mengandung pengajaran yang membuat batas-batas antara Khaliq dan makhluq kadangkala menjadi sulit dijelaskan dan kabur, sehingga di kalangan masyarakat awam sering tidak terkontrol dan salah paham. Padahal maksud mereka berdua adalah, bahwa manusia maupun makhluk ciptaan-ciptaan lainnya tetaplah wujud yang terpisah dari Tuhan. Di sinilah letak pentingnya menggunakan kategori dan perspektif syari'ah. Dalam prinsip-prinsip

Konsepsi Syekh Nuruddin ar-Raniri (Jakarta: Rajawali Press 1983).

${ }^{32}$ Takeshi Ito, "Why did Nuruddin arRaniri leave Aceh in 1054 A.H.?" BKI, 134, 4 (1978): 489-491. Format PDF diunduh dari http: www//kitlv-journals.nl.

33 Azyumardi Azra, The Origins of Islamic Reformism, 40-42. syari'ah, pembedaan antara Khaliq dan makhluq sangatlah ditekankan, terutama saat beribadah dan memahami hubungan antara Khaliq dan makhluq. Selain itu, ibadah syari'ah yang dijalankan dengan sangat tekun dan diiringi dengan zikir yang mendalam merupakan ungkapan dan pengakuan seorang hamba tentang Keesaan Tuhan, sebagai satu-satunya wujud yang disembah. Hasil dari pengalaman ibadah dan perenungan zikir yang mendalam akan menuntun pada suatu pengalaman di mana manusia sepenuhnya menyadari berada di dalam Kesatuan Wujud dengan Tuhan.

Adalah 'Abd al-Ra'uf al-Sinkili (w. 1105/1693) yang meretrospeksi gerakan keras yang dilakukan oleh alRaniri. Al-Sinkili menyindir sikap alRaniri yang memfatwa kafir kepada para pengikut Hamzah Fansuri dan Syams al-Din: "Dan tiada harus kita mengkafir dia, karena mengkafirkan itu sangat bahayanya. Karena jikalau ada ia kafir, maka tiadalah perkataan dalamnya. Dan jikalau tiada ia kafir, niscaya kembali kata itu kepada diri kita. $^{34}$ Al-Sinkili sangat memahami doktrin wahdat al-wujud dan Martabat Tujuh. Dari sejumlah karya-karyanya, ia banyak mengomentari tentang kedua doktrin tersebut, yang tentunya dimaksudkan sebagai penjelasanpenjelasan yang dirasa lebih mudah dipahami oleh banyak orang. ${ }^{35}$ Salah satu upaya terpenting dilakukan oleh al-Sinkili di Aceh adalah melakukan

${ }^{34}$ Dikutip dalam Wan Mohd. Shaghir Abdullah, Khazanah Karya Pusaka Asia Tenggara, jil. 1 (Kuala Lumpur: Khazanah Fathaniyah, 1991), 95.

${ }^{35}$ Lebih jauh tentang pemahaman alSinkili mengenai wahdat al-wujud lihat Oman Fathurahman, Tanbih al-Masyi: Menyoal Wahdatul Wujud, Kasus Abdurrauf Singkel di Aceh Abad 17 (Bandung: Mizan, 1999), 96-98. 
rekonsiliasi antara kelompok yang berorientasi syari'ah dan penganut tasawuf-filosofis. ${ }^{36}$

Tuduhan bahwa tasawuf filosofis cenderung mengabaikan syari'ah adalah kesalahpahaman. Hamzah Fansuri memahami syari'ah, tarekat, hakikat, dan makrifat sebagai satu kesatuan yang tidak terpisah di dalam pengamalan Islam. Dalam karyanya, Syarab al-'Ashiqin, Hamzah Fansri menuntut kepatuhan yang sungguh-sungguh dalam mengerjakan ibadah wajib maupun sunat. Setiap muslim yang ingin mencapai ma'rifat Allah, ia harus mematuhi dan berkhidmat kepada bimbingan guru yang telah memiliki kesempurnaan makrifat. Usaha seorang sufi untuk memperoleh ma'rifat Allah harus melalui jalan syari'ah. Syari'ah digambarkan oleh Hamzah Fansuri sebagai permulaan tarekat. Makna kepatuhan pada syari'ah adalah dalam bentuk mangamalkan ibadah, baik yang wajib maupun sunat. Hamzah Fansuri juga menjelaskan bahwa ibadah-ibadah salat sunat, zikir, puasa sunat, membaca al-Qur'an, mengurangi makan, dan khidmat kepada guru merupakan bahagian penting dalam rangka meraih kedekatan diri kepada Allah. ${ }^{37}$

\section{Muhammad Zayn al-Jambi tentang Mempelajari Tasawuf}

Muhammd Zayn al-Jambi adalah ulama Jambi pada awal abad ke19, yang pernal penulis Qurrat al-'Ayn

${ }^{36}$ Fathurahman Oman, "Ithaf al-dhaki by Ibrahim al-Kurani: A Commentary of Wahdat al- Wujud for Jāwī Audiences," Archipel, volume 81, (2011): 177-198

${ }^{37}$ S. M. N al-Attas, The Misticism of Hamzah Fansuri, 233-234. li Fard al-'Ayn. Manuskrip tersebut adalah satu-satunya informasi yang tentunya sangat minim tentang latar belakang kehidupannya. Zayn al-Jambi selesai menulisnya pada tahun 1232 $\mathrm{H} / 1817$ M. Ia menulis nama lengkapnya Muhammad Zayn bin alhaj 'Abd al-Ra'uf al-Jambi al-Syafi'i al-Asy'ari al-Naqsyabandi. Nama yang panjang tersebut menunjukkan asosianya kepada sejumlah aliran pemikiran di dalam Islam. Mazhab fiqhnya adalah Syafi'iyah, kalam Asy'ariyah, dan Tarekat Naqsyabandiyah. Asosiasinya ke dalam Naqsyabandiyah berarti telah meralat pendapat Bruinessen yang menyebutkan Naqsyabandiyah masuk ke Jambi pada akhir abad ke-19. ${ }^{38}$

$$
\text { Zayn al-Jambi menyebut }
$$

Qurrat al-'Ayn ditulis berdasarkan kitab-kitab oleh ulama ahl al-sunnah wa al-jama'ah. "Bermula kami himpunkan risalah ini daripada beberapa kitab yang diperpegangi oleh segala ulama ahl al-sunnah wa aljama “ah." 39 Di dalamnya mengandung tiga pembahasan penting, yaitu pertama, tentang prinsip-prinsip keimanan yang didasarkan kepada Umm al-Barahîn dan Nur al-Mubîn; kedua tentang fiqh yang merujuk kepada Idah al-Fiqh, al-Mahallî, Minhaj al-Qawwim, Bidayat alMubtadi, dan Quwwat al-Qulub; dan ketiga, pengajaran tasawuf yang mengacu kepada Hidayat al-Salikîn dan Bidayat al-Hidayah. ${ }^{40}$ Berdasarkan rujukannya tersebut, Zayn al-Jambi

38 Martin van Bruinessen, Tarekat Naqsyabandiyah di Indonesia: Survei Historis, Geografis, dan Sosiologis (Bandung: Mizan, 1994), 134.

${ }^{39}$ Ms., Qurrat al- 'Ayn li Fard al- 'Ayn, 42, Museum Negeri Jambi, registrasi 07.052.

${ }^{40}$ Ms., Qurrat al-'Ayn, 42. 
pastilah pernah berguru kepada ulama yang ternama, sehingga ia memiliki bacaan yang cukup luas dan dalam.

Berdasarkan fondasi pemikiran dan sumber-sumber yang digunakannya, Qurrat al-'Ayn memuat pengajaran Islam yang komprehensif tentang meliputi aspek aqidah, syari'ah, dan tasawuf. Menarik sekali, Muhammad 'Ali (w. 2011), seorang ulama dan mursyîd Tarekat Qadiriyah wa Naqsyabandiyah yang paling berpengaruh di Jambi, pernah menyebut karya Zayn al-Jambi tersebut sebagai rujukannya dalam menyikapi persoalan martabat tujuh di Jambi. ${ }^{41}$

\section{Rambu-rambu Memasuki Dunia Tasawuf \\ Zayn al-Jambi menyebut} sumber pemahaman tasawufnya adalah Hidayat al-Salikin karya al-Palimbani (w. ) dan Bidayat al-Hidayah karya alGhazali (w. 1111). ${ }^{42}$ Hidayat al-Salikin disebut sebagai saduran Bidayat alHidayah. Namun dalam penulisannya al-Palimbani juga menggunakan beberapa sumber lainnya untuk penjelasan tambahan. Misalnya, alPalimbani memasukkan beberapa pengajaran dari karya al-Ghazali yang lain yaitu Ihya' 'Ulum al-Dîn dan Minhaj al-'Abid în; karya 'Abd alWahhab al-Sha'rani Yawaqit alJawahir karya, karya 'Abd Allah alAydarus al-Durr al-Tsamin, karya Ahmad al-Qusyasyi Bustan al-Arifin, dan karya Muhammad Samman alNafahat al-Ilahiyah. ${ }^{43}$ Karena itu di

41 Muhammad 'Ali, Nafahat alRahmaniyah (Pesantren Al-Baqiyat al-Shalihat, Kuala Tungkal, t. th.), 8 .

${ }^{42}$ Ms., Qurrat al- 'Ayn, 42.

43 'Abd al-Shamad al-Palimbani, Hidayat al-Salikin fi Suluk Maslak al-Muttaqin, (Surabaya: 1933), 3, 7, 75, dan 273-274. dalam mukadimahnya, al-Palimbani mengatakan bahwa ia tidak hanya sekedar menerjemahkan karya alGhazali agar dapat dipahami oleh banyak orang, tetapi juga memberi beberapa tambahan penjelasan: "membahasakan akan beberapa masalah dengan Bahasa Jawi [dan menambahkan beberapa] masalah yang baik-baik [yang] tak dapat tiada daripadanya.",44

Hidayat al-Salikîn adalah pengajaran fiqh dalam perspektif tasawuf. Misalnya, cara memperoleh kesempurnaan wudu' secara batiniah, yang antara lain, yang diiringi dengan bacaan doa-doa tertentu pada setiap anggota wudu' yang dibasuh dengan air. Begitu pula mengenai ibadah salat, al-Falimbani juga menambahkan penjelasan tentang kondisi batin sebelum berkomunikasi dengan Allah, dan makna-makna terdalam yang terkandung sejak dari mendengarkan adzan, tata cara mengambil posisi berdiri, setiap gerakan-gerakan salat, dan bacaan-bacaan yang menyertainya. Penjelasan-penjelasan seperti ini tentunya tidak diketemukan dalam kitab-kitab fiqh yang "biasa". Selain itu, di dalam Hidayat al-Salikîn, alPalimbani juga menjelaskan tentang cara-cara membersihkan hati dari dengki, marah, sombong, dan riya'. Kondisi hati sangat penting untuk mengikuti tingkatan-tingkatan (maqam) yang akan dilalui oleh seorang salik dalam menekuni taubat, khawf, zuhd, sabar, syukur, ikhlas, tawakal, mahabbah, dan rida, ${ }^{45}$ yang mana bahagian ini tidak dijumpai dalam Bidayat al-Hidayah.

\footnotetext{
44 'Abd al-Shamad al-Palimbani, Hidayat al-Salikin, 3.

45 'Abd al-Shamad al-Palimbani,
} Hidayat al-Salikin, 47. 
Namun sayangnya, di dalam Qurrat al-'Ayn, Zayn al-Jambi hanya membuat pernyataan singkat saja, berupa nasehatnya bagi orang-orang yang akan mempelajari tasawuf dan menempuh jalan tarekat, khususnya dalam memahami konsep martabat tujuh, wahdat al-wujud, dan fana'.

Bermula ingat-ingat daripada mengaji Martabat Tujuh dan menjalani maqam ahl al-shufi dan dengan wahdat al-wujud hingga sampai mem-fana'-kan segala ma siwa Allah, karena kebanyakan manusia tiada sampai fahamnya seperti kehendak mereka itu, maka jatuhlah kepada i'tiqad wujudiyah, dan bathiniyyah, dan jabariyyah. ${ }^{46}$

Menurut pengamatan Zayn alJambi, kebanyakan orang-orang yang mempelajari doktrin-doktrin tersebut bukannya sampai kepada pemahaman yang benar tentang wujud alam dan wujud Allah, tetapi malah terjatuh kepada kesalahpamaham teologis, dan tergelincir ke dalam golongan wujudiyah, bathiniyyah, dan jabariyyah.

Sayang sekali, meskipun Zayn al-Jambi juga menyebut tentang wahdat al-wujud dan Martabat Tujuh di dalam Qurrat al- 'Ayn, tetapi ia tidak memberikan komentarnya lebih lanjut mengenai dokrin tersebut. Ia hanya sebatas mengingatkan agar hati-hati mempelajarinya dan carilah guru yang tepat, karena tidak sedikit orang yang mempelajarinya jatuh pada pemahaman yang keliru. Sepertinya, Zayn al-Jambi tidak memasukkan pengajaran tentang Martabat Tujuh dan wahdat al-wujud di dalam Qurrat al-'Ayn karena ia merasa risalahnya hanya ditujukan kepada "mukallaf yang baru belajar" Islam (mubtadi). Tentang hal ini, Zayn al-Jambi mengatakan:

Maka adalah yang kami sehaja dengan risalah ini bagi segala mukallaf yang baharu berlajar jua. Demikian memudahilah bagi segala mereka itu. Dan jikalau mati, maka sahlah imannya, dan i'tiqadnya, dan agamanya. $^{47}$

Dengan kata lain, Qurrat al'Ayn diperuntukkan bagi kalangan Muslim awam dan pemula (mubtadi), maka Zayn al-Jambi tidak memasukkan pengajaran mengenai Martabat Tujuh, wahdat al-wujud, fana', dan pemahaman yang menyampaikan kepada ma siwa Allah. Boleh jadi, dalam penilaian Zayn al-Jambi, tingkat intelektualisme Muslim di Jambi pada abad ke-19, kebanyakan masih dalam ambang mubtadi, yang dirasa belum siap untuk menerima doktrin-doktrin tasawuf yang sangat rumit.

Meskipun demikian, bukan berarti Zayn al-Jambi melarang untuk mempelajari doktrin Martabat Tujuh dan wahdat al-wujud. Terkait dengan hal ini, Zayn al-Jambi menjelaskan perlunya pengkategorian dan persyaratan-persyaratan tertentu bagi orang-orang yang ingin mempelajari doktrin-doktrin tasawuf yang lebih rumit.

... segala mukmin yang 'amm jangan masuk kepada bicara yang demikian itu, melainkan bagi segala mukmin yang khash supaya tautnya ia membicarakan akan yang demikian itu. Karena yang

${ }^{47}$ Ms., Qurrat al- 'Ayn, 39-40.
${ }^{46}$ Ms., Qurrat al- 'Ayn, 38-39. 
menyempurnakan tawhid-nya dan ma 'rifah-nya, dan menuntut martabat yang lebih sempurna. Tetapi disyaratkan bagi mereka itu hendaklah mahir pada bicara 'ilm al-ushul al-din dan tetap pada menegakkan syari'at. ${ }^{48}$

Berdasarkan kutipan di atas, Zayn al-Jambi memandang perlu adanya pengkategorian mukmin yang 'amm (pemula) dan khash (orang-orang tertentu), dalam kaitan mempelajari ilmu tasawuf. Menurut Zayn al-Jambi, hanya orang-orang yang telah mencapat tingkatan khash atau kelompok khusus yang boleh mempelajari doktrin Martabat Tujuh, maqam ahl al-shufi, wahdat al-wujud, dan fana', karena mereka dipandang telah memiliki dasar-dasar keimanan dan ke-tawhid-an yang sempurnan dan telah mematuhi syari'at. Tidak cukup hanya sebatas itu, untuk mempelajarinya haruslah melalui guru yang kamil mukammil. Jika tidak terpenuhi syarat-syarat demikian itu lebih baik tidak mempelajarinya. “...Mengaji kepada guru yang kamil mukammil. Dan jika tiada demikian maka janganlah mengaji bicara itu," demikian Zayn al-Jambi menegaskan. ${ }^{49}$ Komentar dengan nada yang sama tentang pengajaran Martabat Tujuh juga pernah disampaikan oleh Muhammad Zayn al-Asyi di Aceh dan Syihab al-Din di Palembang pada pertengahan abad ke-18. Di dalam karyanya, Bidayat al-Hidayah, Muhammad Zayn al-Asyi menyarankan lebih baik tidak mempelajarinya karena sudah sulit menemukan guru yang mumpuni untuk mengajarinya: "Ada pun pada berlajar

\footnotetext{
${ }^{48}$ Ms., Qurrat al-'Ayn, 47.

${ }^{49}$ Ms., Qurrat al-'Ayn, 47.
}

martabat tujuh itu, tiada wajib menuntut dia. Lagi pula tiada ahlinya pada masa ini." 50 Syihab al-Din juga merasakan ketertarikan yang kuat kalangan masyarakat Palembang untuk mempelajari martabat tujuh. Di dalam karyanya, Risalah, Syihab al-Din menyinggung sufi-sufi pemula yang mempelajarinya telah berani membuat pernyataan-pernyataan yang tidak lazim, seperti "La fa il illallah; atau $L a$ mawjud illallah," yang seharusnya, hanya boleh diucapkan oleh sufi yang telah sempurna pemahaman tawhid dan syari'at. Bagi Syihab al-Din, sufi pemula yang membuat pernyataanpernyataan tersebut merupakan bid'ah, zindiq, dan kufr. ${ }^{51}$

\section{E. Kesimpulan}

Da'ud Sunur, seorang ulama yang merekonsiliasi syari'at dan tasawuf di tanah Pariaman, pada pertengahan abad ke-19. ${ }^{52}$ Da'ud menyarankan perlunya tahapan-tahapan tertentu sebelum mempelajari Martabat Tujuh. Untuk itu, ia membagi murid atas tiga tingkatan, yaitu mubtadi, mutawassith, dan muntahi. Murid yang telah mencapai tahap muntahi boleh mempelajari Martabat Tujuh, sedangkan yang masih dalam tahap mubtadi dan mutawassith hanya akan menjadi racun dan menimbulkan

50 "Syeikh Muhammad Zain bin Faqih Jalaluddin al-Asyi dan Pengaruh Bidayat alHidayah, dikutip dalam Wan Mohd. Shaghir Abdullah, Penyebaran Islam dan Silsilah Ulama Sejagat Dunia Melayu: jilid 7 (Kuala Lumpur: Khazanah Fathaniyah, 1999), 12.

51 Transkripsi Ms. Risalah, dikutip dalam G. W. J Drewes, Directions for Travellers, 89-90.

52 Suryadi, Syair Sunur: Teks dan Konteks Otobiografi Seorang Ulama Minangkabau Abad ke-19 (Padang: Citra Budaya Indonesia dan YDIKM, 2004). 
mudarat. Kebanyakan murid-murid yang masih dalam kategori mubtadi dan mutawassith kurang bisa mencerna dan seringkali menjadi "sesat" dalam mempelajari tasawuf filosfis. Karena itu guru-guru sufi di abad ke-19 memandang perlu untuk memberikan pembatasan dan persyaratan tertentu sebelum mempelajarinya. Berdasarkan pertimbangan inilah Zayn al-Jambi juga mengingatkan muslim di Jambi agar terlebih dahulu menyempurnakan tauhid, mematuhi syari'at, dan mencari guru yang benar-benar dapat memberikan pemahaman tentang wahdat al-wujud dan Martabat Tujuh secara benar.

\section{Daftar Kepustakaan}

Abdullah, Hawash. Perkembangan Ilmu Tasawuf dan Tokohtokohnya di Nusantara. Surabaya: Al-Ikhlas, t. th.

'Ali, Muhammad. Nafahat alRahmaniyah. Pesantren AlBaqiyat al-Sālihāt, Kuala Tungkal, t. th.

al-Attas, S. M. N. "Raniri and the Wujudiyyah of the $17^{\text {th }}$ Century Acheh," Monograph of $M M B R A S$, no. 3, Singapore, (1966).

. S. M. N al-Attas, The Mystic of Hamzah Fansuri. Kuala Lumpur: University of Malaya Press, 1970.

Azra, Azyumardi. The Origins of Islamic Reformism in Southeast Asia: Networks of Malay and Middle Eastern 'Ulama' in the Seventeenth and Eighteenth Centuries. Honolulu: Allen \& Unwin, 2004. . "Naskah dan Rekonstruksi Sejarah Sosial-Intelektual
Nusantara," dikutip dalam Uka Tjandrasasmita, Kajian Naskahnaskah Klasik dan Penerapannya bagi Kajian Sejarah Islam di Indonesia. Jakarta: Puslitbang Lektur Keagamaan, Kemenag RI, 2006.

Bakar, Osman. "Sufism in the MalayIndonesian World," in S. H. Nasr (ed.), Islamic Spirituality II: Manifestations. London: SCM, 1991.

Braginsky, V. I. "Towards the Biography of Hamzah Fansuri. When Did Hamzah Live? Data from His Poems and Early European Accounts," Archipel, Vol. 57, (1999).

van Bruinessen, Martin. Tarekat Naqsyabandiyah di Indonesia: Survei Historis, Geografis, dan Sosiologis. Bandung: Mizan, 1994.

Dahlan. Abdul Aziz Penilaian Teologis atas Paham Wahdat al-Wujud (Kesatuan Wujud) Tuhan, Alam, Manusia dalam Tasawuf Syamsuddin Sumatrani. Padang: IAIN-IB Press, 1999.

Daudy, Ahmad. Allah dan Manusia dalam Konsepsi Syekh Nuruddin ar-Raniri. Jakarta: Rajawali Press 1983.

Drakard, Jane. Sejarah Raja-raja Barus: Dua Naskah dari Barus. Jakarta: EFEO, 1988.

Fathurahman, Oman. Tanbih al-Masyi: Menyoal Wahdatul Wujud, Kasus Abdurrauf Singkel di Aceh Abad 17. Bandung: Mizan, 1999. " "Naskah dan Rekonstruksi Islam Lokal: Telaah Awal atas Kitab Ithaf al-Zaki karya Ibrahim al-Kurani," Makalah 
Simposium MANASSA,

Universitas Andalas, Padang, 31 Juli 2001.

Guillot dan Ludvik Kalus menyebut Hamzah Fansuri wafat pada tahun 1527, lihat, Inskripsi Islam Tertua di Indonesia, penerj. Laddy Lesmana, dkk. Jakarta: KPG, 2008.

Ito, Takeshi. "Why did Nuruddin arRaniri leave Aceh in 1054 A.H.?" in Bijdragen tot de Taal-, Land- en Volkenkunde, 134, 4 (1978).

Johns, A. H. "Sufism as Category in Indonesian Literature and History," JSEAH, vol. II, no. 2, (1961)

. "Sufism in Southeast Asia: Reflections and Reconsiderations," JSEAS, Vol. 26, No. 1, (1995).

. "Malay Sufism as Illustrated in an Anonymous Collection of $17^{\text {th }}$ Century Tract," JMBRAS, vol. XXX, part 2, (1957).

. "Reflection on Mysticism of Shams al-Din al-Samatra'i (1550?-1630)," Studia Islamika, vol. 18, no. 2, (2011).

Mu'jizah, Martabat Tujuh: Edisi Teks dan Pemaknaan Tanda serta Simbol. Jakarta : Yanasa, 2005.

Nieuwenhuijze, C. A. O. Samsu'l Din van Pasai, Bijdrage tot de Kennis der Sumatransche Mystiek. Leiden: E. J. Brill, 1945.

Azhari Noer, Kautsar. Wahdat alWujud dalam Perdebatan. Jakarta: Paramadina, 1995.

al-Palimbani, Abd al-Shamad. Hidayat al-Salikin fi Suluk Maslak alMuttaqin. Surabaya: 1933.

Quzwain, Muhammad Khatib. Mengenal Allah: Suatu Studi
Mengenai Ajaran Tasawuf

Syaikh Abdussamad al-

Palimbani (Jakarta: Rajawali Perss, 1985).

Riddell, Peter. G. Islam and the MalayIndonesian World:

Transmission and Responses. Honolulu: University of Hawaii Press, 2001.

Sahlins, Marshall. Islands History. Chicago: University of Chicago Press, 1985.

Shaghir Abdullah, Wan Mohd. Khazanah Karya Pusaka Asia Tenggara, jil.1, Kuala Lumpur: Khazanah Fathaniyah, 1991.

Suryadi, Syair Sunur: Teks dan Konteks Otobiografi Seorang Ulama Minangkabau Abad ke19. Padang: Citra Budaya Indonesia dan YDIKM, 2004.

Suryadi "Kitab 'Manasik Haji' Pertama dalam Bahasa Melayu," dalam Sejarah dan Peradaban: Sejarah dan Dialog Peradaban: Persembahan 70 Tahun Taufik Abdullah. ed. A. B Lapian. Jakarta: LIPI, 2005.

W.M., Abdul Hadi. Tasawuf yang Tertindas: Kajian Hermeneutik terhadap Karya-karya Hamzah Fansuri. Jakarta: Paramadina, 2001.

dan L.K Ara (penyt.), Hamzah Fansuri: Penyair Sufi Aceh. t. tmp. Lotkala.

Ms., Qurrat al-'Ayn li Fard al-'Ayn, 42, Museum Negeri Jambi, registrasi 07.052. 